

\title{
Does a Rival's Song Elicit Territorial Defense in a Tropical Songbird, the Pied Bush Chat (Saxicola caprata)?
}

\author{
Navjeevan Dadwal $^{1 *}$ and Dinesh Bhatt ${ }^{1}$
}

\author{
${ }^{1}$ Gurukula Kangri University, Haridwar, Uttarakhand, India \\ *Corresponding author (Email:navjeevan.dadwal@gmail.com)
}

Citation - Dadwal, N., \& Bhatt, D. (2017). Does a rival's song elicit territorial defense in a tropical songbird, the Pied Bush Chat (Saxicola caprata)? Animal Behavior and Cognition, 4(2), 146-153. https://doi.org/10.12966/ abc.02.05.2017

\begin{abstract}
The purpose of bird song and the way in which it is delivered has been argued to be adapted mainly for territorial defense. We performed a field experiment with the combination of playbacks and a model to test how much song actually relates to increased territorial defense in the territorial tropical songbird, the Pied Bush Chat, during breeding season (Feb-May, 2015) at Haridwar, Himalayan Foothills, India. As expected, the results of the experiment indicated that song was the major cue used by territory holders to cope with rival intrusions. The song rate was particularly escalated during simulated territorial interactions when the model was presented with a playback song of conspecifics. Behaviors such as restlessness (perch change), the height of perch, and distance from the model appeared to be of relatively lesser importance. To our knowledge, no avian species from the Indian subcontinent has been studied to provide evidence that song can escalate aggressive response by a territory owner.
\end{abstract}

Keywords-Territorial defense, Tropical songbird, Pied Bush Chat

The science and art of bird song have been explored for decades and it is evident that bird songs are expressed for (1) mate attraction and (2) male-male rivalry during territorial acquisition and defense (Catchpole, 1982; Darwin, 1888; Eriksson \& Wallin, 1986; Gil \& Gahr, 2002; Krebs \& Kroodsma, 1980; Laidre \& Vehrencamp, 2008; Searcy \& Andersson, 1986).

The increased responses of females towards intense and complex singing of males have been demonstrated by the field experiments of female removal (Cuthill \& Hindmarsh, 1985; Searcy, 1984). From such experiments it has been concluded that absence or presence of the female may affect the singing behaviour of the male. This helps to reveal the functionality of song in mate attraction (Krebs, Avery, \& Cowie, 1981; Mountjoy \& Lemon, 1991).

On the other hand, territorial playbacks are the most common method of addressing the question regarding the function of song in territoriality. Field experiments to understand the role of song in territoriality are generally comprised of playback experiments at particular locations in the center or periphery in the resident male's territory (Wunderle Jr., 1978). Collins (2004) reviewed and compiled information about such experiments along with their advantages and limitations. There are generally three main methods used to address the role of song in male-male rivalry. First are observational methods (Galeotti, Saino, Sacchi, \& Møller, 1997) which simply attend to the aggressive encounters, accompanied by quality of vocal displays during a territorial dispute. Second are territorial song playbacks, during which the response of the territory holders is recorded after a simulated song is broadcasted in the 
territory. However, what actually gets tested is how songs of intruders are perceived, recognized and responded to by the resident males (Searcy, Nowicki,\& Hogan, 2000), whereas the issue of how song is used in territory defense remains almost unaddressed. The solution of this problem relies in a method of speaker replacement. Third is use of the speaker replacement method. In this method a male is removed from its nest/territory and is replaced with a speaker, broadcasting particular song stimuli followed by the quantifications of intrusions/vocal responses of the neighbours towards speaker (Searcy et al., 2000). Unfortunately, this approach is sometimes impractical, as the intrusions into a territory are infrequent and difficult to observe (Collins, 2004).

If song of territory holders is meant for territory defense, then the presence of such songs should be sufficiently strong to limit any rival's intrusions. On the contrary, from the traditional playbacks it appears that upon broadcasting an unfamiliar rival's songs in an occupied territory the territory holders strongly confront/defend their territory via escalated vocal/physical response (Searcy et al., 2000). This situation is intriguing in terms of behavior and cognition because of two scenarios: (1) It could be that song of a territory holder is being delivered from its own territory for territory defense, or (2) it could be that when song of a rival is broadcasted in an occupied territory, the signal is inferred as a sign/threat of territory acquisition by a territory holder. Using standard playback procedures, we can actually test whether songs are used in territory defense and whether broadcasting a foreign song forces the territory holders to escalate their vocal response to confront territory acquisitions by a foreign male.

Additionally, most of the studies of singing behavior of birds have concentrated on temperate zones species which live in highly seasonal environments (Morton, 1996). Despite the fact that many bird species are residents of tropical habitats, so far no avian species from Indian subcontinent has been studied to provide evidence that song can escalate response by a territory owner (Chiver, Stutchbury, \& Morton, 2015; Stutchbury \& Morton, 2001). Given this limitation in studying birds from only limited areas, and with the goal of providing new evidence from an unstudied species we performed a field experiment using the combination of existing playback methods and the use of a crafted model of the study species (the Pied Bush Chat). The goal of this study was to demonstrate how, whether, and to what degree the song of a rival caused an escalated response from territory-owners and what measures were adopted by these residents to counter such rivalries from intruders.

\section{Method}

\section{Setting}

This study was carried out during the breeding season of 2015 (February to May) in the natural habitat of Pied Bush Chats at different sites adjacent to the town of Haridwar (29055' N and 78008'E; Himalayan Foothill of India).

\section{Subjects}

The Pied Bush Chat (Order Passeriformes, Family Muscicapidae) is a tropical songbird that occurs discontinuously from Transcaspia and the Indian subcontinent to South-East Asia, the Philippines, Indonesia, New Guinea and New Britain. The breeding season is mainly February to August with a peak in March to June. The Pied Bush Chat is a bird of the open cultivated landscapes, especially paddy and sugar cane fields. It is a resident breeder in tropical southern Asia from the Greater Middle East through Pakistan, India and Bangladesh eastwards to Indonesia (Ali \& Ripley, 2001).

Fourteen different male Pied Bush Chats were selected for this experiment. We observed the breeding activities of all the selected pairs of Pied Bush Chats. Several hours were spent daily throughout the breeding season searching for the nest in an attempt to detect all breeding activities occurring at the various territories. 


\section{Procedure}

The nesting cycle of Pied Bush Chats was divided into five stages: pre-nesting (when males were attracting their females and establishing their territories), nest building (when pairs were building their nest), egg laying (when females were laying eggs), incubation (when females were incubating their eggs) and provisioning (when pairs were feeding the nestlings).

In general, song delivery (when no artificial model or song was present) of 14 males that we observed consisted of complex dawn chorus with an average song repertoire size of $22.16 \pm 4.32$ on a daily basis during breeding season (February to July). Males deliver their song for about 25 minutes at high rates of song types per minute. Males start their dawn chorus in darkness (about an hour before sun rise) and deliver complex song bouts with varying distinct song types per minute. Day singing by males is less frequent. Males also perform continuous singing throughout the breeding season to interact vocally with their neighbors. Our field observations indicated that song delivery in Pied Bush Chat plays an important role in maintenance and adjustment of social relationship among neighboring males. Apparently, Pied Bush Chats sing maximally, and on a daily basis during dawn as compared to other times of the day. We frequently observed males interacting through counter-singing for extended periods, suggesting the importance of songs for maintenance and adjustment of social status/bond. Trespassers (rivals) from adjacent territories are immediately chased off by the resident males and, shortly thereafter, both males resume singing on their own song perches. Hence, it can be inferred that males use singing to communicate with their close neighbors, to defend the territory, or to challenge neighbors on a daily basis throughout the breeding season.

A model was designed of wood and painted with natural colors (black and white) to the morphology of the Pied Bush Chat. We have used the same model to lure the individuals of study species into mist nets for other studies, and we were certain that the models are recognized/investigated and attacked by the male Pied Bush Chats (Figure 1). Also, such models have been used for studying the sister species of genus Saxicola such as Stone Chats Saxicola torquata (Villavicencio, Blas, \& Goymann, 2014).

During the nest building stage of their breeding cycle, the studied pairs were presented with simulated territorial conflicts. The simulations consisted of placing the model at a height of approximately $1.5 \mathrm{~m}$ (average perch height of Pied Bush Chat). In some cases, the model was muted (i.e., there was only a visible presence with no song) or the model was presented with a playback song. In that case, the speakers were mounted just below the model so that the songs were projected from as near to the model as we could arrange. It was expected that during the nest building stage males would be most aggressive (physically/vocally) towards any intrusion/rival as the pairs were about to perform copulation prior to egg laying.

At each observation, an initial $10 \mathrm{~s}$ of playback of unfamiliar songs was broadcasted to attract the attention of the territory holders. Then the model was placed for six minutes near the nesting cavity of Pied Bush Chats during the nest building stage of their nesting cycle. For the first three minutes the model was muted and the aggression of the residents was quantified in terms of song rate (the number of song phrases delivered), territorial call rate (the number of territorial calls uttered), number of flights towards the model, restlessness (perch change: the number of times the resident males changed their perches), distance of male Pied Bush Chats from the model (the minimum distance maintained by the residents from the location of the model), and maximum height of perch used by the resident males to respond. In the next three min, the model produced unfamiliar/unshared song types (Sethi, Bhatt, \& Kumar, 2014), and we recorded the same behaviors as during the first three min.

Only one male was tested per day. Each male was observed in one session. All observations were made from a distance of 20 to $25 \mathrm{~m}$. Behaviors were recorded manually and by a video camera mounted on a tripod. All observations occurred between $10 \mathrm{AM}$ and $3 \mathrm{PM}$ (local time). All sessions were conducted on the days with calm weather. 
Under the IUCN red list of threatened species, the Pied Bush Chat (Saxicola caprata) falls under the least concern (LC) category, and none of the birds were sacrificed or brought to the laboratory under any circumstances.

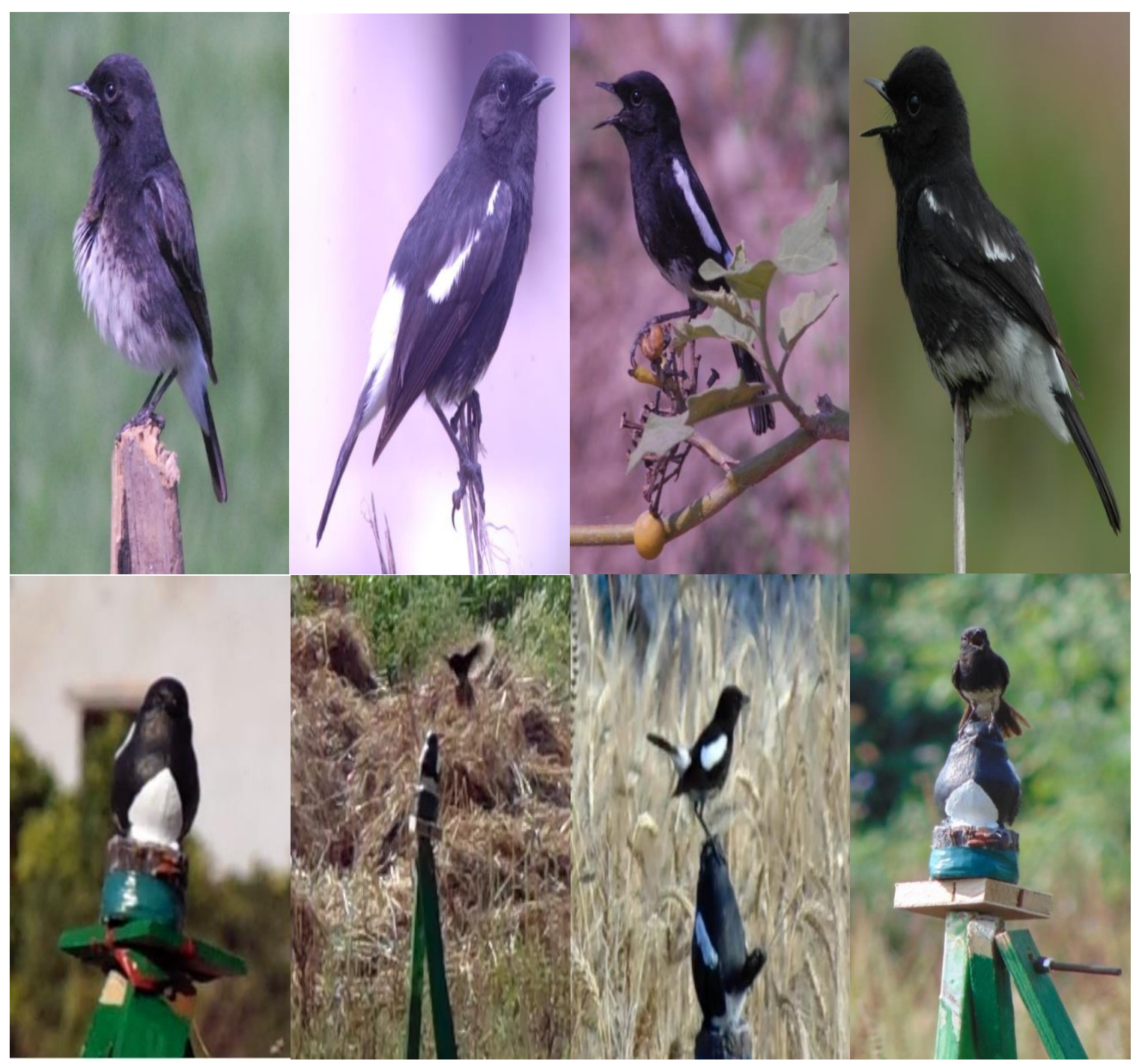

Figure 1. Top row - Morphology of male Pied Bush Chat (while not singing and singing). Bottom row - Model and singing posture of Pied Bush Chats during simulated territorial conflicts.

\section{Results}

The results are presented as means with associated \pm SE for all behaviors that were observed and scored. Between silent and playback modes we performed Wilcoxon Signed-ranks test (Paired samples) to check the level of significance of various parameters.

\section{Song Rate (Per 3 Min)}

The delivered song rate by the territory holders for both silent and playback modes was $M=6.4$, $S E=1.71$ and $M=12.9, S E=3.45(N=14)$ respectively (Figure 2$)$. The song rate was higher in case of 
playback mode (i.e., model + playback song) as there was a significant variation, Wilcoxon Signed-ranks test (Paired samples): $\mathrm{W}=87, \mathrm{Z}=2.16, p=0.02$, in the delivered song rate between both the scenarios.

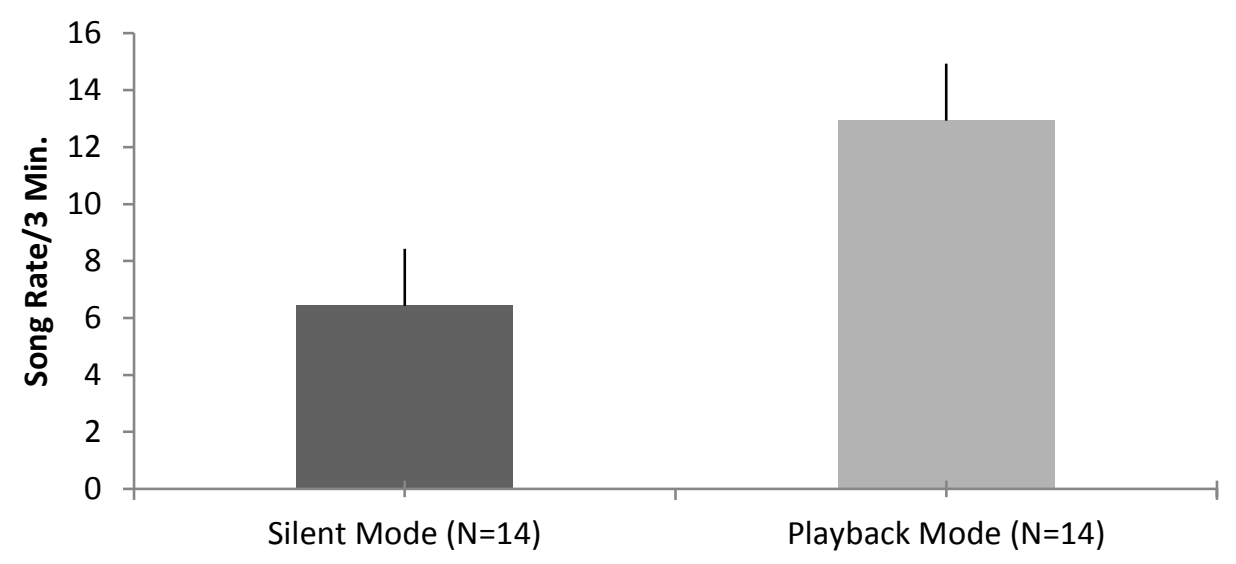

Figure 2. Showing the song rate $( \pm S E)$ delivered by male Pied Bush Chats during encounter with the dummy.

\section{Territorial Calls}

The quantified call rate uttered during silent and playback mode by the territory defenders were $M=2.21, S E=0.59$ and $M=0.6, S E=0.17(N=14)$, respectively. A non-significant Wilcoxon Signedranks test (Paired samples): $\mathrm{W}=26, \mathrm{Z}=2.04, p=0.06$, variation was found in the call rates between both sets of the experiments.

\section{Flights Towards Model}

The numbers of flights taken by the resident males towards the model during silent and playback modes were $M=0.6, S E=0.17$ and $M=3.6, S E=0.97(N=14)$, respectively (Figure 3$)$. This was a significant difference, Wilcoxon Signed-ranks test (Paired samples): $\mathrm{W}=54, \mathrm{Z}=2.7, p=0.004$, between silent and playback modes of the experiment.

\section{Restlessness (Perch Change)}

The measured restlessness among the territorial males under silent and playback modes was $M=3.7, S E=0.99$ and $M=6.4, S E=1.71(N=14)$, respectively. This was a non-significant difference, Wilcoxon Signed-ranks test (Paired samples): $\mathrm{W}=45.5, \mathrm{Z}=1.1, p=0.29$, in the behavior between modes.

\section{Distance of Male Pied Bush Chats from the Model}

The minimum distance of the territory owners during silent and playback modes from the location of the model was $M=8.3, S E=2.23$ and $M=8.4, S E=2.26(N=14)$, respectively. This was a nonsignificant difference, Wilcoxon Signed-ranks test (Paired samples): $\mathrm{W}=46, \mathrm{Z}=0.04, p=0.98$. 


\section{Height of Perch}

The quantified height of the perch used by the male Pied Bush Chats was $M=6.5, S E=1.75$ and $M=6.2, S E=1.67(N=14)$ during silent and playback modes respectively. This was a non-significant difference, Wilcoxon Signed-ranks test (Paired samples): $\mathrm{W}=43, \mathrm{Z}=0.31, p=0.70$.

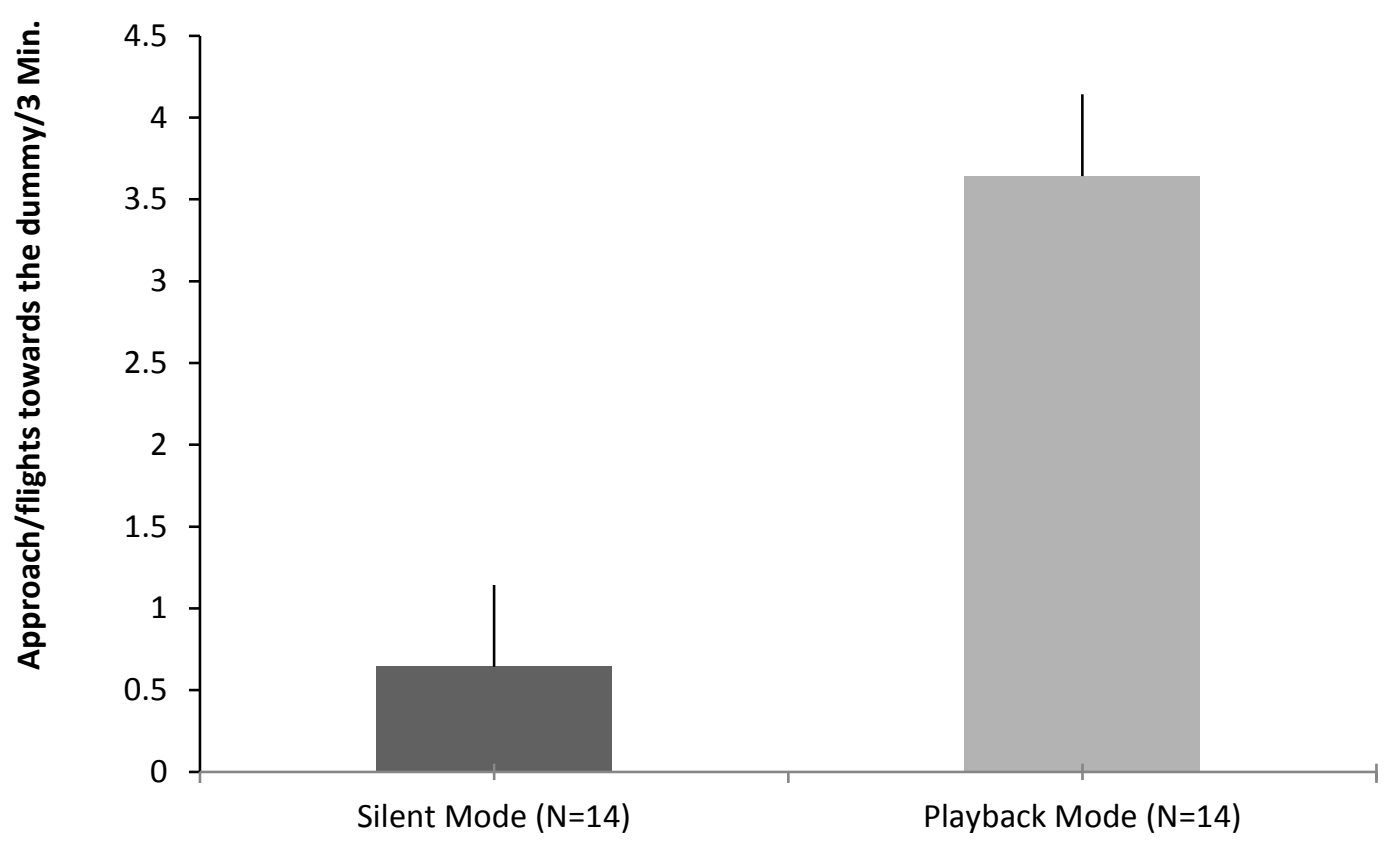

Figure 3. Showing the approach/flights $( \pm S E)$ towards the dummy by male Pied Bush Chats during encounter.

\section{Discussion}

The results revealed that there was a significant difference in the numbers of songs and flights towards the model between silent and playback modes of the experiment while a non-significant difference was obtained for the display of other gestures such as restlessness, the height of perch and distance from the model between both the modes. Additionally, the flights towards the model were also mostly accompanied with songs perhaps to strengthen the song displays, whereas the remaining tested behavioral gestures seem to be of lesser importance during the simulated territorial conflicts.

The analysis of videos of experimental runs showed that before flight displays, male Pied Bush Chats tried to scare the intruders away (Figure 1, bottom row) with territorial calls. Afterward, males attacked their supposed opponent by flying straight at it, and such flights were mostly accompanied with songs during aggression displays by the residents. As evidence of territorial function, the song in Pied Bush Chats has been reported to occur throughout the breeding season during which territories are maintained and is confined to the defended area (Sethi, Bhatt, \& Kumar, 2012). The evidence from previous studies suggests that territorial males perform counter-singing with their neighbors (Wasserman, 1977) and also sing in response to the simulated territorial intrusions (Falls, 1981). Similar behavior has been reported in sister species of Pied Bush Chats such as Stonechats, where throughout breeding season males defend their territory by a combination of displaying and chasing away the intruders (Greig-Smith, 1982). 
Despite the criticism of traditional playback methods in determining the role of song in territorial defense (Searcy et al., 2000), the use of playbacks does allow us to visualize how much song actually adds to cause an escalated territorial defense by territory holders. The response (singing) of resident males was escalated when the dummy was accompanied with song playback. It may be that as part of territory defense the resident male Pied Bush Chats responded back with higher song rates. It should be noted that in this context song was required to acquire a territory by an intruder, and also the song was required by the residents to defend their territory. Thus, such escalated singing behavior suggests that song of Pied Bush Chats could be a major cue in territory acquisition along with the territory defense.

According to the territory defense hypothesis a seasonal increase in song output could result in increased frequency of territorial challenges (Levin, 1996). In other words, if male song increases primarily as a result of territorial defense, then seasonal song activity should be positively correlated with the territorial intrusions and escalated aggressions (Chiver et al., 2015). Such results have been reported in Song sparrows (Hyman, Hughes, Searcy, \& Nowicki, 2004; Nowicki, Searcy, Krueger, \& Hughes, 2002).

In the present study song rates escalated when the model was accompanied with a playback song whereas the song rate of resident Pied Bush Chats was significantly lower in the case of muted model. Thus, the escalation of song rate by Pied Bush Chats during aggressive situations suggests that songs specifically elicit a stronger territorial response in Pied Bush Chats. In addition, Pied Bush Chats appear to use songs to respond aggressively to intruders. As suggested by Searcy and Beecher (2009), to establish this behavior of Pied Bush Chats in terms of territorial and aggressive context, more investigations are needed. It may be that male songs play a prime role in territory defense along with the territorial acquisitions. It was interesting to note that male Pied Bush Chats used song as first arrow from their quiver to counter the simulated territorial disputes. Prior to this study, no direct evidence was available that songs of the Pied Bush Chat, a tropical songbird of Indian subcontinent, are used in territorial interactions and escalate the vocal response of territory owners.

\section{Acknowledgements}

Authors are thankful for (1) Department of Science and Technology, Govt. of India and University Grant Commission-Special Assistance Programme for Funding this research; (2) Head, Department of Zoology and environmental science, Gurukula Kangri University, Haridwar for providing infrastructural facility to carry out this research, and (3) Prof. Mewa Singh, Department of Psychology

and Institute of Excellence, University of Mysore, Mysuru) for his guidance in the statistical analysis of the data.

\section{References}

Ali, S., \& Ripley, S. D. (2001). Handbook of the birds of India and Pakistan. New Delhi, India: Oxford University Press.

Catchpole, C. (1982). The evolution of bird sounds in relation to mating and spacing behavior. Acoustic Communication in Birds, 1, 297-317.

Chiver, I., Stutchbury, B. J., \& Morton, E. S. (2015). The function of seasonal song in a tropical resident species, the Red-throated Ant-tanager (Habiafuscicauda). Journal of Ornithology, 156, 55-63.

Collins, S. (2004). Vocal fighting and flirting: The function of bird song. In P. R. Marlet \& H. Slabbekoorn (Eds.), Nature's music: The science of birdsong (pp. 39 - 78). San Diego, CA: Elsevier Academic Press.

Cuthill, I., \& Hindmarsh, A. (1985). Increase in starling song activity with removal of mate. Animal Behaviour, 33, 326-328.

Darwin, C. (1888). The descent of man, and selection in relation to sex. Princeton, NJ: Princeton University Press.

Eriksson, D., \& Wallin, L. (1986). Male bird song attracts females-a field experiment. Behavioral Ecology and Sociobiology, 19, 297-299.

Falls, J. B. (1981). Mapping territories with playback: An accurate census method for songbirds. Studies in Avian Biology, 6, 86-91.

Galeotti, P., Saino, N., Sacchi, R., \& Møller, A. P. (1997). Song correlates with social context, testosterone and body 
condition in male Barn Swallows. Animal Behaviour, 53, 687-700.

Gil, D., \& Gahr, M. (2002). The honesty of bird song: Multiple constraints for multiple traits. Trends in Ecology \& Evolution, 17, 133-141.

Greig-Smith, P. W. (1982). Interspecific aggression between chats. Bird Study, 29, 162-164.

Hyman, J., Hughes, M., Searcy, W. A., \& Nowicki, S. (2004). Individual variation in the strength of territory defense in male song sparrows: Correlates of age, territory tenure, and neighbor aggressiveness. Behaviour, $141,15-27$.

Krebs, J. R., Avery, M., \& Cowie, R. J. (1981). Effect of removal of mate on the singing behaviour of Great Tits. Animal Behaviour, 29, 635-637.

Krebs, J. R., \& Kroodsma, D. E. (1980). Repertoires and territory defense. Nature, 271, 539-542.

Laidre, M. E., \& Vehrencamp, S. L. (2008). Is bird song a reliable signal of aggressive intent? Behavioral Ecology and Sociobiology, 62, 1207-1211.

Levin, R. N. (1996). Song behaviour and reproductive strategies in a duetting wren, Thryothorusnigrica pillus: I. Removal experiments. Animal Behaviour, 52, 1093-1106.

Morton, E. S. (1996). Why songbirds learn songs: An arms race over ranging? Poultry and Avian Biology Reviews, 7, 65-71.

Mountjoy, D.J., \& Lemon, R.E. (1991). Song as an attractant for male and female European Starlings, and the influence of song complexity on their response. Behavioural Ecology and Sociobiology, 28, 97-100.

Nowicki, S., Searcy, W. A., Krueger, T., \& Hughes, M. (2002). Individual variation in response to simulated territorial challenge among territory-holding song sparrows. Journal of Avian Biology, 33, 253-259.

Searcy, W. A. (1984). Song repertoire size and female preferences in Song Sparrows. Behavioural Ecology and Sociobiology, 14, 281-286.

Searcy, W. A., \& Andersson, M. (1986). Sexual selection and the evolution of song. Annual Review of Ecology and Systematics, 17, 507-533.

Searcy, W. A., \& Beecher, M. D. (2009). Song as an aggressive signal in songbirds. Animal Behaviour, 78, 12811292.

Searcy, W. A., Nowicki, S., \& Hogan, C. (2000). Song type variants and aggressive context. Behavioural Ecology and Sociobiology, 48, 358-363.

Sethi, V. K., Bhatt, D., \& Kumar, A. (2012). Dawn singing behavior of a tropical bird species, the Pied Bush Chat Saxicolacaprata. Journal of Applied and Natural Science, 4, 241-246.

Sethi, V. K., Bhatt, D., \& Kumar, A. (2014). Song sharing in the pied bush chat (Saxicolacaprata). Belgian Journal of Zoology, 1, 67-76.

Stutchbury, B. J., \& Morton, E. S. (2001). Behavioral ecology of tropical birds. London, UK: Academic Press.

Villavicencio, C. P., Blas, J., \& Goymann, W. (2014). The number of life-history stages does not influence the androgen responsiveness to male-male interactions: Sedentary and migratory black redstarts (Phoenicurusochruros) do not elevate testosterone in response to simulated territorial intrusions. General and Comparative Endocrinology, 205, 159-165.

Wasserman, F. E. (1977). Mate attraction function of song in the white-throated sparrow. The Condor, 79, 125127.

Wunderle Jr., J. M. (1978). Differential response of territorial yellowthroats to the songs of neighbors and nonneighbors. The Auk, 389-395. 